\title{
Flora vascular de humedales permanentes y transitorios bonaerenses (Buenos Aires, Argentina)
}

\author{
Lilian M. Passarelli ${ }^{1 *}$, Cristina H. Rolleri ${ }^{1}$, María de las Mercedes Ciciarelli ${ }^{1}$, \\ Ana Clara Dedomenici ${ }^{1}$ y Graciela González ${ }^{1,2}$
}

Resumen: Passarelli, L. M.; Rolleri, C. H.; Ciciarelli M. M.; Dedomenici A. C. \& González, G. 2014. Flora vascular de humedales permanentes y transitorios bonaerenses (Buenos Aires, Argentina). Bot. Complut. 38: 139-154.

Este trabajo presenta un análisis de las fitocenosis y listas actualizadas de la flora vascular (con excepción de las Poaceae) de dos humedales permanentes, La Balandra y la Isla Santiago, y de varios humedales temporarios (arroyo Rodríguez, arroyo El Gato, y otros) de las zonas costeras del Río de La Plata (provincia de Buenos Aires, Argentina). El estudio se basó en el trabajo de campo y el seguimiento estacional de las comunidades silvestres entre los años 2005 y 2011, con un registro de 126 taxones de flora vascular determinados en ese lapso. Las Dicotiledóneas representan el grupo dominante en ambos humedales, seguido en número por las Monocotiledóneas y escasos representantes de pteridófitos. En el humedal de La Balandra se registraron 102 especies de plantas vasculares que incluyen 33 familias de dicotiledóneas (53 géneros), 17 de monocotiledóneas (22 géneros) y 5 de pteridófitos ( 5 géneros), mientras que en el humedal de Isla Santiago se registraron un total de 116 especies pertenecientes a 36 familias de dicotiledóneas ( 64 géneros), 16 de monocotiledóneas ( 25 géneros) y 6 de pteridófitos ( 7 géneros). Las fitocenosis de los humedales permanentes y transitorios se compararon con la biodiversidad registrada en áreas costeras protegidas, como la Reserva Provincial de Punta Lara. La biodiversidad de la Isla Santiago es claramente mayor que la de La Balandra y está seriamente amenazada por acción antropogénica y por el progreso de la zona como área habitacional. La biodiversidad en los humedales transitorios es la más disminuida en relación con la flora prístina y su vulnerabilidad se incrementa cada año.

Palabras clave: biodiversidad, fitocenosis, áreas costeras, flora vascular, Río de La Plata.

Abstract: Passarelli, L. M.; Rolleri, C. H.; Ciciarelli, M. M.; Dedomenici, A. C. \& González, G. 2014. Vascular flora of permanent and temporary wetlands from Buenos Aires (Argentina). Bot. Complut. 38: 139-154.

This paper presents an analysis of phytocoenoses and updated lists of the vascular flora (with the exception of Poaceae) of two permanent wetlands, La Balandra and Isla Santiago, and several temporary wetlands (Arroyo Rodríguez, Arroyo El Gato, and others) in the coastal areas of the Rio de La Plata (Buenos Aires Province, Argentina). The study was based on field work and monitoring seasonal wild communities between years 2005 and 2011, with 126 vascular plant taxa identify during the period. Dicotyledons represent the dominant group in both wetlands, followed in number by Monocotyledons and a few Pteridophyta representatives. In the wetland of La Balandra 102 species of vascular plants, including 33 families of Dicotyledons ( 53 genera), 17 of Monocotyledons ( 22 genera) and 5 belonging to Pteridophyta ( 5 genera) were recorded, while in Isla Santiago wetland a total of 116 species were collected belonging to 36 Dicotyledon families (64 genera), 16 to Monocotyledons ( 25 genera) and 6 to Pteridophyta (7 genus). The phytocoenoses of permanent and temporary wetlands were compared with recorded biodiversity in protected coastal areas, such as the Reserva Provincial de Punta Lara. The biodiversity of Isla Santiago is clearly larger than La Balandra, and is seriously threatened by anthropogenic activity and progress in the zone as a residential area. The temporary wetlands biodiversity is the most diminished in relation to pristine flora, and vulnerability is increasing every year.

Key words: biodiversity, phytocoenoses, coastal areas, vascular flora, Rio de la Plata.

\footnotetext{
${ }^{1}$ Laboratorio de Estudios de Anatomía Vegetal Evolutiva y Sistemática (LEAVES), Facultad de Ciencias Naturales, Universidad Nacional de la Plata, 64 entre 120 y diagonal 113, B1904 DZB, La Plata, Argentina.

${ }^{2}$ Departamento de Ecología Genética y Evolución, Facultad de Ciencias Exactas y Naturales, Universidad de Buenos Aires, Intendente Güiraldes 2160, C1428EGA, Ciudad Autónoma de Buenos Aires, Argentina.

* Correspondencia autor: Impassarelli@yahoo.com.ar

Recibido: 22 noviembre 2013. Aceptado: 12 diciembre 2013.
} 


\section{INTRODUCCIÓN}

El término humedales se aplica a una gran variedad de hábitats interiores, costeros y marinos con determinadas características: se trata de extensiones de marismas, pantanos y turberas o superficies cubiertas de agua, de régimen natural 0 artificial, permanentes 0 temporales, estancadas 0 corrientes, dulces 0 saladas, incluidas las extensiones de agua marina cuya profundidad en marea baja no exceda los seis metros. Se encuentran entre los ecosistemas más productivos de la Tierra y brindan, a través de sus recursos, funciones y atributos, importantes beneficios económicos y sociales a las comunidades cuya vida depende de los mismos. $\mathrm{Su}$ conocimiento es esencial, ya que los humedales de la Argentina, como los del resto del mundo, están entre los ecosistemas más vulnerables y amenazados del planeta.

El agua, que juega un papel fundamental en la definición de la estructura y las funciones ecológicas de los humedales, determina sus características y su variabilidad tanto en el tiempo como en el espacio, tiene efectos definitivos sobre su diversidad biológica y genera las respuestas fisiológicas (adaptaciones) que los organismos vegetales desarrollan para sobrevivir ante cambios eventualmente extremos, como los ciclos hidrológicos de gran amplitud, en los que alternan períodos de sequía y de gran inundación (Mitsch \& Gosselink 1993, Roggeri 1995, Barbier et al.1997, Canevari et al. 1998, 1999; Malvárez 1999, Kandus et al. 2003).

En la Argentina, la Cuenca del Plata es la principal cuenca hídrica; se halla en un territorio predominantemente llano, con suelos fértiles y clima benigno, en donde se encuentran lagunas, esteros, pantanos y bañados, todos con rasgos de humedales.

La ribera platense comprende un conjunto de ecosistemas que originalmente ocupaba la zona que hoy se extiende desde el Sur del Gran Buenos Aires hasta el Norte del partido de Magdalena y que comprende unas tres mil hectáreas que concentran la mayor diversidad biológica de la provincia de Buenos Aires. Forman parte del Sistema de Áreas Protegidas de la provincia y comprenden la zona costera de la selva marginal de Hudson, el Parque Provincial Pereyra Iraola y la Reserva Provincial de Punta Lara. Esta última constituye el relicto más austral de las selvas en galería que bordean los ríos Paraná y Uruguay y concentra una gran diversidad de especies, muchas de ellas típicas y provenientes de la selva misionera, que llegan a estas latitudes por medio del transporte por esos ríos, de semillas o partes de plantas. El ambiente es adecuado también para el crecimiento y desarrollo de la fauna, con numerosas especies de invertebrados (fundamentalmente artrópodos) y vertebrados (principalmente aves), como también hongos, musgos y líquenes. Otros humedales permanentes y transitorios de la zona ribereña de la provincia de Buenos Aires no se encuentran protegidos y debido a la creciente urbanización de algunas zonas, la flora silvestre autóctona está en peligro.

Existen numerosos aportes florísticos, fitogeográficos, análisis de las ecorregiones y otros aspectos de los humedales bonaerenses, relacionados con la presencia y abundancia de especies exóticas, la heterogeneidad ambiental y las comunidades vegetales de humedales del delta del $\mathrm{Pa}$ raná, la caracterización de áreas de humedales en las relaciones flora y fauna, las reservas o zonas protegidas costeras y otros más específicos, como los de Frenguelli (1941), Castellanos \& Pérez Moreau (1945), Parodi (1945, 1964), Cabrera \& Dawson (1944), Burkart (1957), Cabrera et al. (1963-1970), Rataj (1972), Burkart et al. (1990), Cabrera \& Zardini (1978), Mujica (1979), Barbetti et al. (1985), Faggi \& Cagnoni (1990), Goya \& Brown (1992), Chichizolla (1993), Bertolini \& Deginani (1994), Beerling (1995), Ciciarelli (1995), Menalled \& Adámoli (1995), Roggeri (1995), Cagnoni et al. (1996), Kandus (1997), Lahitte \& Hurrell (1997), Malvárez (1999), Quintana \& Bó (1998), Quintana et al. (1999), Kandus et al. (2000), Kalesnik (2001), Arbo \& Tressens (2002), Frusella \& Chébez (2003), Vallés et al. (2005), Ciciarelli (2007), Ciciarelli \& Rolleri (2008) Ciciarelli et al. (2010) entre otros.

Este trabajo es resultado de estudios de campo efectuados entre 2005 y 2011, con recolecciones estacionales y seguimiento de las comunidades de la flora vascular presentes en el área con el fin principal de actualizar su biodiversidad, aunque se han excluido las Poaceae, excepto en los casos de elementos estrechamente asociados particularmente con las fitocenosis ribereñas. En el lapso mencionado se han podido registrar los efectos de los cambios climáticos locales, especialmente las precipitaciones, sobre la dinámica de las comunidades vegetales de estos humedales, actualizar los taxones presentes y su grado de conservación. El estudio de la vegetación de la región costera del Río de La Plata se centró en dos grandes humedales permanentes no estudiados previamente: La Balandra e Isla Santiago (Fig. 1B y C). Las fitocenosis halladas se compararon con las presentes en humedales transitorios de la zona, como los de arroyo Rodríguez, arroyo El Gato y otros (Fig. 1A) y con la biodiversidad registrada en áreas protegidas, como la Reserva Provincial de Punta Lara.

\section{MATERIALES Y MÉTODOS}

Características del área de estudio. Los partidos de La Plata, Berisso y Ensenada integran una región designada común- 


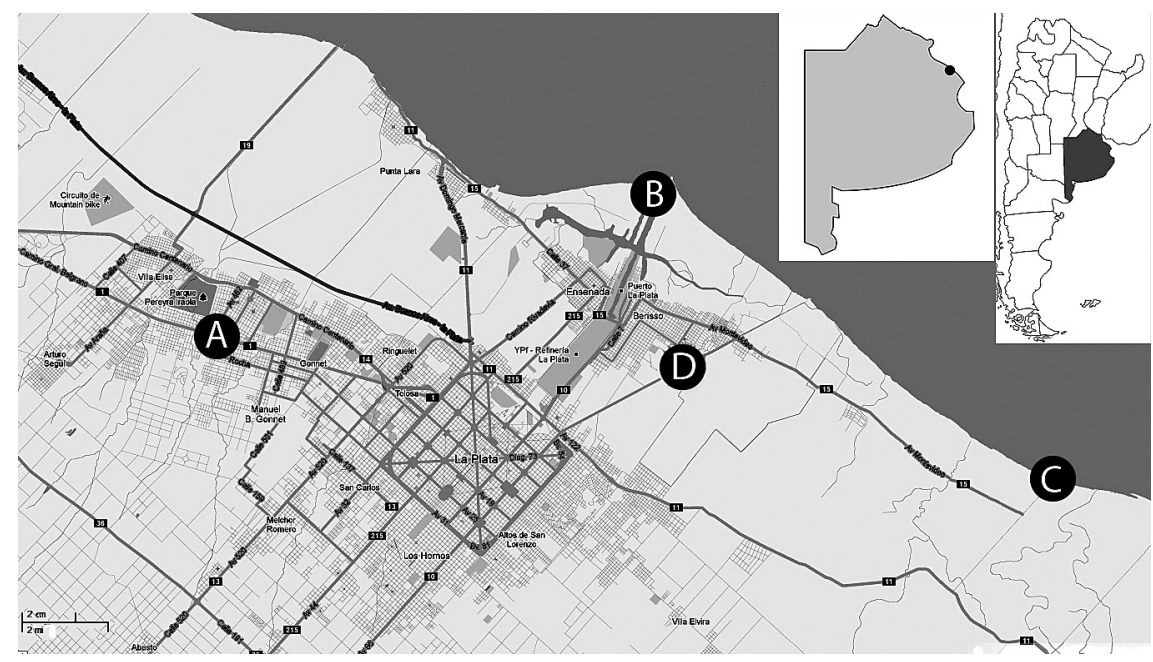

Fig. 1- Mapa del área de estudio en la ribera rioplatense. A: humedales transitorios; B: humedal permanente de Isla Santiago; C: humedal permanente de La Balandra; D: humedal transitorio Calle 66.

Tabla 1

Temperatura y precipitaciones medias anuales en la Cuenca del Plata

\begin{tabular}{lrrrrrrr}
\hline Años & \multicolumn{1}{c}{$\mathbf{2 0 0 5}$} & $\mathbf{2 0 0 6}$ & \multicolumn{1}{c}{$\mathbf{2 0 0 7}$} & $\mathbf{2 0 0 8}$ & $\mathbf{2 0 0 9}$ & $\mathbf{2 0 1 0}$ & $\mathbf{2 0 1 1}$ \\
\hline $\mathbf{T m}\left({ }^{\circ} \mathrm{C}\right)$ & 17,9 & 18,2 & 17,4 & 18,5 & 18,2 & 16,2 & 16,2 \\
$\mathbf{P m}(\mathrm{mm})$ & 1084,5 & 1281 & 1313,1 & 722,1 & 1313,5 & 1055,8 & 801,6 \\
\hline
\end{tabular}

mente como Gran La Plata, próxima a la Ciudad Autónoma de Buenos Aires pero con características diferentes. Desde el punto de vista fitogeográfico la zona pertenece a la Región Neotropical, con vegetación terrestre de selvas ribereñas, marginales 0 en galería. El clima es templado pampeano, con una humedad relativa promedio del $76-80 \%$, con precipitaciones medias anuales entre 720-1300 $\mathrm{mm}$ y temperaturas medias anuales entre $17,4-18,5^{\circ} \mathrm{C}$, durante el período estudiado (Tabla 1). El río actúa como un regulador natural de los cambios de temperatura, pero los vientos pueden ser intensos, particularmente en los períodos llamados de sudestada, un fenómeno meteorológico localizado en el Río de la Plata, generalmente entre marzo y octubre, que se caracteriza por vientos regulares a fuertes del SE, provenientes del río, que ocasionan con frecuencia la inundación de toda la ribera, con temperaturas relativamente bajas y precipitaciones de variada intensidad, o los períodos de vientos secos o pamperos, con origen en el Pacífico Sur, que soplan en ráfagas intensas desde el So SO y pueden generar bajantes importantes del nivel del río.

Desde el punto de vista estructural, el área posee un basamento cristalino con rocas metamórficas del Proterozoico inferior que constituye la base de los sedimentos posteriores. Durante el Plioceno se depositaron las llamadas Arenas Puelches, cuarzosas, de origen fluvial, con espesores de hasta $20 \mathrm{~m}$, que almacenan agua de excelente calidad y representan la reserva acuífera más importante de la región pampeana. Por encima, se acumulan sedimentos limosos cuaternarios, con proporciones variables de arena $y / 0$ arcilla y concreciones de carbonato de calcio; tienen espesores de hasta $50 \mathrm{~m}$ y forman los bancos de tosca típicos del Río de La Plata, relacionados con períodos de aridez (AABA 2010). La porción más superficial está constituida por limos, en parte arenosos con abundante tosca y, en la zona costera y en los valles de los ríos principales, por sedimentos marinos, provenientes del avance del mar sobre el continente durante el Holoceno y Pleistoceno, que determinan bancos de conchillas y areniscas litorales. Los pisos más recientes son terrenos aluviales que ocupan toda la orilla costera, con una altura de entre 2,5-5 $\mathrm{m}$ sobre el nivel del agua, que forman una terraza baja, deprimida, que se extiende entre los partidos de Berisso y La Plata, en la que se originan bañados, debido a la naturaleza arcillosa e impermeable del terreno, que impide el drenaje.

Desde los bañados hacia la costa, el terreno asciende en forma suave dando origen a un albardón, paralelo a la ribera, de menos de $2 \mathrm{~m}$ sobre el nivel del mar, surcado de arroyos y canales, permanentes y temporarios, que desembocan en el Río de La Plata. El arroyo Río Santiago, que separa la tierra firme de la Isla Santiago y la Isla Paulino, tiene unos $12 \mathrm{~km}$ de extensión, alcanza un ancho máximo de $200 \mathrm{~m}$ y constituye un pequeño brazo del Río de La Plata. Otros arroyos importantes, de NE a 
NO, son La Balandra, Saladero, El Pescado, que es el más caudaloso y desemboca, desde la zona de terraza alta, por medio del arroyo La Maza en el Río de La Plata, así como varios cursos secundarios como canal Antonini, canal Este, canal Bagliardi y arroyo La Bellaca. Este último está situado en la cañada del mismo nombre, una depresión que en épocas de crecida permite la salida de las aguas o bien recibe las del Río de La Plata y alimenta 0 drena el gran bañado Maldonado, aislado de la costa por un albardón sobre el que se asienta la ciudad de Berisso (Fig. 1). En esta zona, dos grandes humedales permanentes, el humedal de La Balandra y el humedal de Isla Santiago y varios transitorios presentan, por su posición topográfica y la inundación constante, ecosistemas con una notable diversidad biológica.

Se realizaron recolecciones en los diferentes hábitats de los humedales de acuerdo a técnicas estandarizadas (Bridson \& Forman 1992), entre 2005 y 2011. Los viajes de recolección de material vegetativo se efectuaron durante todo el año. Se registraron las coordenadas geográficas y altitudes mediante un receptor GPS. Los ejemplares recolectados se encuentran depositados en el herbario de la Facultad de Ciencias Naturales y Museo de La Plata (LP). Las determinaciones taxonómicas fueron realizadas en el Laboratorio de Estudios de Anatomía Vegetal Evolutiva y Sistemática (LEAVES) de la Facultad de Ciencias Naturales y Museo de La Plata, empleando claves o descripciones de las floras locales, entre otras las de Cabrera (1963-1970), Burkart et al. (1987), Burkart et al. (2000), Cabrera \& Zardini (1978), Haynes \& Holm Nielsen (1994), Lahitte \& Hurrell (1997), Arbo \& Tressens (2002), Judd et al. (2002) y Zuloaga et al. (2008).

Se consideraron las especies autóctonas o silvestres, introducidas, naturalizadas y cultivadas (Font Quer 2000), analizando asimismo la persistencia temporal de los tipos biológicos hallados y teniendo en cuenta las asociaciones florísticas de cada área. Las fitocenosis se tomaron de Cabrera et al. (1978), y se consideraron las plantas acuáticas flotantes 0 arraigadas, el césped ribereño, el pajonal mixto, el matorral herbáceo y el bosque hidrófilo.

Los datos de la temperatura media anual, precipitaciones medias anuales, y las precipitaciones para la Cuenca del Plata entre los años 2005 y 2011 provienen del Servicio Meteorológico Nacional, Argentina (http//www.smn.gov.ar) y se exponen en la Tabla 1. Las listas de los taxones presentes se ordenan en la Tabla 2.

\section{RESULTADOS}

Se encuentran fitocenosis diversas, integradas por plantas acuáticas, sumergidas y flotantes, anfibias o palustres y terrestres. En los terrenos parcialmente inundables y los humedales próximos al río se encuentran relictos de formaciones selváticas, con estratos herbáceos, arbustivos, arbóreos y escasos epífitos que llegan hasta el río mismo en continuidad con las comunidades marginales acuáticas (Tabla 2).
Humedal de La Balandra (Fig. 2). Se encuentra en la localidad de Berisso, a $18 \mathrm{~km}$ de la ciudad de ese nombre ( $\left.34^{\circ} 9^{\prime} \mathrm{S} 57^{\circ} 7^{\circ} \mathrm{O}\right)$. La costa de Berisso tiene $22 \mathrm{~km}$ sobre el Río de La Plata y La Balandra tiene $15 \mathrm{~km}$ de longitud; es la playa más amplia del distrito e incluye otras zonas con playas protegidas y ocasionales humedales transitorios como los de Playa Municipal, Playa Bagliardi, Playa Palo Blanco e Isla Paulino (Fig. 1C). El ambiente es lótico, con
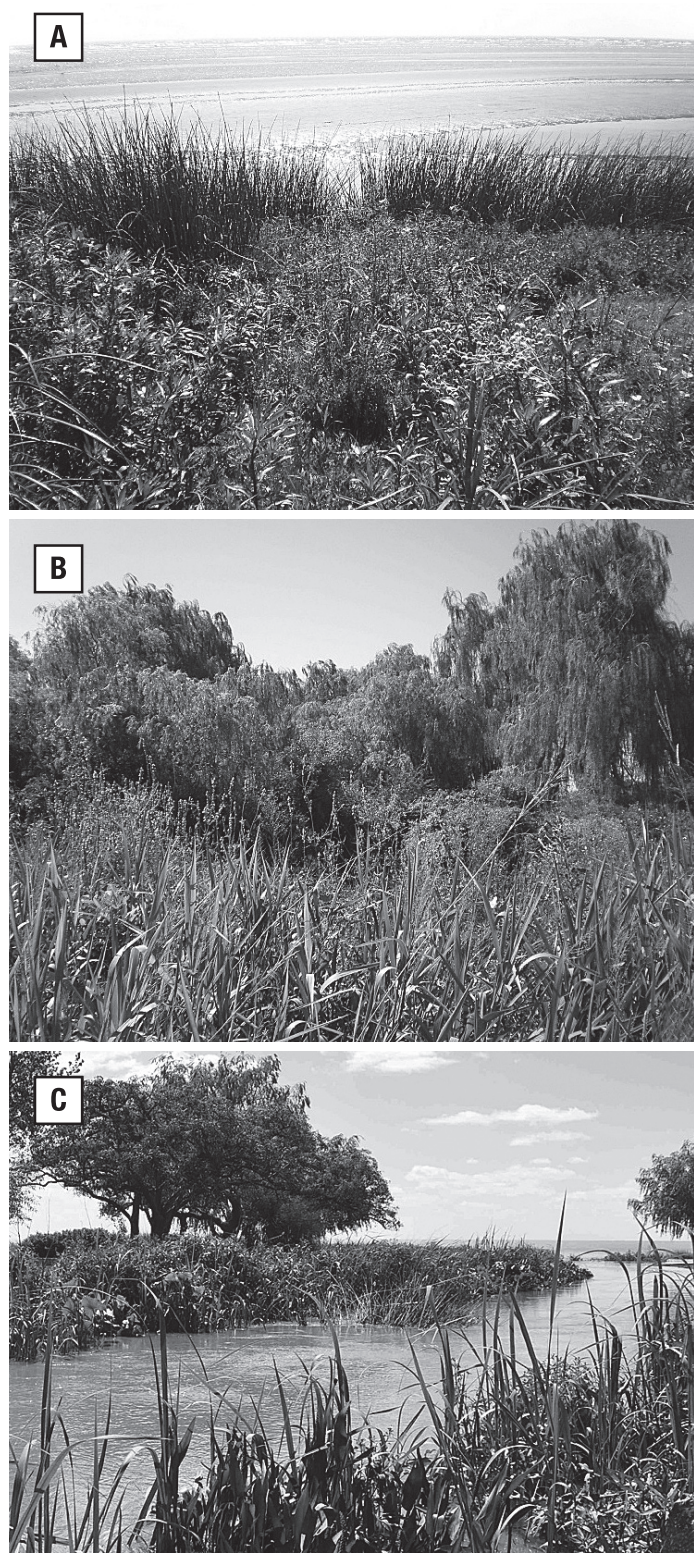

Fig. 2- Humedal permanente de La Balandra. A: juncal costero, césped ribereño y pajonal mixto; B: bosque hidrófilo cerca de un camino; $\mathbf{C}$ : canal que desemboca en el río de La Plata. 
Tabla 2

Lista de taxones de la flora vascular (exceptuando Poaceae) de los humedales permanentes y transitorios bonaerenses. 1: HT (humedal transitório), IS (humedal permanente de Isla Santiago, LB (humedal permanente de La Balandra). 2: A (arbusto), AR (árbol), E (enredadera), EP (epífita), H (hierba), SA (subarbusto). 3: A (acuática), P (palustre), T (terrestre). 4: AA (acuática arraigada), AF (acuática flotante), B (bosque), BH (bosque hidrófilo), CR (césped ribereño), $\mathrm{MH}$ (matorral herbáceo), PM (pajonal mixto).

5: A (autóctona), E (endémica), I (introducida), N (naturalizada)

\begin{tabular}{lccccc}
\hline Taxones & Humedal & Hábito & Hábitat Fitocenosis Origen \\
& (1) & (2) & (3) & (4) & (5) \\
\hline
\end{tabular}

\section{Dicotiledóneas}

\section{Acanthaceae}

Dicliptera squarrosa Nees

\section{Aceraceae}

Acer negundo L.

\section{Amaranthaceae}

Alternanthera philoxeroides (Mart.) Griseb.

Amaranthus hybridus L. subsp. hybridus

Gomphrena elegans Mart.

\section{Apiaceae}

Conium maculatum L.

Eryngium pandanifolium Cham. \& Schltdl.

Hydrocotyle leucocephala Cham. \& Schltdl.

$H$. ranunculoides L. f.

Lilaeopsis brasiliensis (Glaz.) Affolter

\section{Asclepiadaceae}

Oxypetalum erianthum Decne.

\section{Asteraceae}

Acmella decumbens (Sm.) R. K. Jansen

Aspilia silphioides Benth. \& Hook. $\mathrm{f}$

Baccharis punctulata DC.

Bidens laevis (L.) Briton, Stern \& Poggenb.

Coniza bonariensis (L.) Cronquist

Enhydra anagallis Gardner

Gymnocoronis spilanthoides (Hook \& Arn.) DC.

Mikania micrantha Kunth

Senecio bonariensis Hook. \& Arn.

Solidago chilensis Meyen

Tessaria integrifolia Ruiz \& Pav.

\section{Begoniaceae}

Begonia cucullata Willd.

\section{Brassicaceae}

Cardamine bonariensis Pers.

C. hirsuta L.

$\begin{array}{ccccc}\text { IS-LB } & \mathrm{H} & \mathrm{P} & \text { PM-CR } & \mathrm{N} \\ \text { IS-LB-HT } & \mathrm{AR} & \mathrm{T} & \mathrm{B} & \mathrm{I} \\ & & & & \\ \text { IS-LB-HT } & \mathrm{H} & \mathrm{A} & \mathrm{AA} & \mathrm{A} \\ \text { IS-HT } & \mathrm{H} & \mathrm{T} & \text { PM } & \mathrm{N} \\ \text { IS-LB } & \mathrm{H} & \mathrm{T} & \mathrm{CR} & \mathrm{A}\end{array}$

$\begin{array}{ccccc}\text { IS-LB-HT } & \mathrm{H} & \mathrm{T} & \mathrm{MH} & \mathrm{I} \\ \text { IS-LB } & \mathrm{H} & \mathrm{T} & \text { AF } & \text { A } \\ \text { IS-LB } & \mathrm{H} & \mathrm{A} & \text { CR } & \text { A } \\ \text { IS-LB } & \mathrm{H} & \mathrm{T} & \text { CR } & \text { A } \\ \text { LB } & \mathrm{H} & \mathrm{A} & \text { PM } & \text { N }\end{array}$

Cactaceae

Rhipsalis lumbricoides (Lem.) Lem.

$\begin{array}{ccccc}\text { HT } & \text { E } & \text { T } & \text { HT } & \text { A } \\ & & & & \\ \text { IS-LB } & \text { H } & \text { T } & \text { PM-BH } & \text { A } \\ \text { IS-LB } & \text { H } & \text { T } & \text { PM } & \text { A } \\ \text { IS-LB } & \text { H } & \text { T } & \text { PM } & \text { A } \\ \text { IS-LB } & \text { H } & \text { T } & \text { PM } & \text { A } \\ \text { IS-LB } & \text { H } & \text { T } & \text { PM } & \text { A } \\ \text { IS-LB } & \text { H } & \text { A } & \text { AA } & \text { A } \\ \text { IS-LB } & \text { H } & \text { T } & \text { MH } & \text { A } \\ \text { IS-LB } & \text { H } & \text { T } & \text { MH } & \text { A } \\ \text { IS-HT } & \text { H } & \text { T } & \text { MH } & \text { E } \\ \text { IS-LB-HT } & \text { H } & \text { T } & \text { MH } & \text { A } \\ \text { IS-LB } & \text { A-AR } & \text { T } & \text { BH } & \text { A }\end{array}$

$\begin{array}{lllll}\text { IS } & \text { H } & \text { T } & \text { PM } & \text { A } \\ & & & & \\ \text { IS } & \text { H } & \text { T } & \text { CR } & \text { A } \\ \text { IS } & \text { H } & \text { T } & \text { CR } & \text { I }\end{array}$

IS $\quad$ EP $\quad T \quad$ MH $\quad$ A


Tabla 2 (cont.)

\begin{tabular}{|c|c|c|c|c|c|}
\hline Taxones & $\begin{array}{l}\text { Humedal } \\
\text { (1) }\end{array}$ & $\begin{array}{l}\text { Hábito } \\
(2)\end{array}$ & $\begin{array}{l}\text { Hábitat } \\
\text { (3) }\end{array}$ & $\begin{array}{l}\text { Fitocenosis } \\
\quad(4)\end{array}$ & $\begin{array}{l}\text { Origen } \\
(\mathbf{5})\end{array}$ \\
\hline $\begin{array}{l}\text { Caprifoliaceae } \\
\quad \text { Lonicera japonica Thunb }\end{array}$ & IS-LB & E & $\mathrm{T}$ & BH & A \\
\hline $\begin{array}{l}\text { Combretaceae } \\
\text { Terminalia australis Cambess. }\end{array}$ & IS-LB & A & $\mathrm{T}$ & BH & E \\
\hline $\begin{array}{l}\text { Convolvulaceae } \\
\text { Ipomoea alba L. } \\
\text { I. indica (Burm. f.) Merr. } \\
\text { I. purpurea (L.) Roth. } \\
\text { Calystegia hederacea Wall ex Roxb. }\end{array}$ & $\begin{array}{l}\text { IS-LB } \\
\text { IS-LB } \\
\text { IS-LB-HT } \\
\text { IS-LB }\end{array}$ & $\begin{array}{l}\mathrm{E} \\
\mathrm{E} \\
\mathrm{E} \\
\mathrm{E}\end{array}$ & $\begin{array}{l}\mathrm{T} \\
\mathrm{T} \\
\mathrm{T} \\
\mathrm{T}\end{array}$ & $\begin{array}{l}\mathrm{MH} \\
\mathrm{MH} \\
\mathrm{MH} \\
\mathrm{MH}\end{array}$ & $\begin{array}{l}\text { A } \\
\text { A } \\
\text { A } \\
\text { A }\end{array}$ \\
\hline $\begin{array}{l}\text { Cucurbitaceae } \\
\text { Cayaponia bonariensis (Mill) Mart. Crov. }\end{array}$ & IS-LB & $\mathrm{E}$ & $\mathrm{T}$ & A & A \\
\hline $\begin{array}{l}\text { Euphorbiaceae } \\
\text { Manihot flabellifolia Pohl. } \\
\text { Ricinus communis L. }\end{array}$ & $\begin{array}{l}\text { IS-LB-HT } \\
\text { IS-LB }\end{array}$ & $\begin{array}{l}\mathrm{H}-\mathrm{A} \\
\mathrm{H}-\mathrm{A}\end{array}$ & $\begin{array}{l}\mathrm{T} \\
\mathrm{T}\end{array}$ & $\begin{array}{l}\mathrm{MH} \\
\mathrm{MH}\end{array}$ & $\begin{array}{l}\text { A } \\
\mathrm{N}\end{array}$ \\
\hline $\begin{array}{l}\text { Fabaceae } \\
\text { Aeschynomene montevidensis Vogel } \\
\text { Erythrina crista-galli L. } \\
\text { Galega officinalis L. } \\
\text { Trifolium repens L. } \\
\text { Sesbania punicia (Cav.) Benth. }\end{array}$ & $\begin{array}{l}\text { IS-LB } \\
\text { IS-LB-HT } \\
\text { IS-LB } \\
\text { IS } \\
\text { IS }\end{array}$ & $\begin{array}{c}\text { AR } \\
\text { A } \\
\mathrm{H} \\
\mathrm{H} \\
\mathrm{AR}\end{array}$ & $\begin{array}{l}\mathrm{T} \\
\mathrm{T} \\
\mathrm{T} \\
\mathrm{T} \\
\mathrm{T}\end{array}$ & $\begin{array}{l}\mathrm{MH} \\
\mathrm{BH} \\
\mathrm{MR} \\
\mathrm{PM} \\
\mathrm{MH}\end{array}$ & $\begin{array}{l}\mathrm{A} \\
\mathrm{A} \\
\mathrm{N} \\
\mathrm{N} \\
\mathrm{A}\end{array}$ \\
\hline $\begin{array}{l}\text { Fumariaceae } \\
\text { Fumaria capreolata } \mathrm{L} .\end{array}$ & IS-LB & $\mathrm{H}$ & $\mathrm{T}$ & PM & $\mathrm{N}$ \\
\hline $\begin{array}{l}\text { Haloragaceae } \\
\text { Myriophyllum aquaticum (Vell.) Verdc. }\end{array}$ & IS-LB & $\mathrm{H}$ & A & $\mathrm{AA}$ & A \\
\hline $\begin{array}{l}\text { Lamiaceae } \\
\text { Hyptis fasciculata Benth. } \\
\text { Salvia guaranitica A. St. Hil. ex Benth. }\end{array}$ & $\begin{array}{l}\text { IS-LB } \\
\text { IS-LB }\end{array}$ & $\begin{array}{l}\mathrm{H} \\
\mathrm{H}\end{array}$ & $\begin{array}{l}\mathrm{T} \\
\mathrm{T}\end{array}$ & $\begin{array}{l}\mathrm{MH} \\
\mathrm{MH}\end{array}$ & $\begin{array}{l}\text { A } \\
\text { A }\end{array}$ \\
\hline $\begin{array}{l}\text { Lythraceae } \\
\text { Cuphea fruticosa Spreng. }\end{array}$ & LB & $\mathrm{H}$ & $\mathrm{T}$ & CR & A \\
\hline $\begin{array}{l}\text { Malvaceae } \\
\text { Modiolastrum malvifolium (Griseb.) K. Schum. } \\
\text { Pavonia sepia A. St. Hil. }\end{array}$ & $\begin{array}{l}\text { IS } \\
\text { IS-LB }\end{array}$ & $\begin{array}{l}\mathrm{H} \\
\mathrm{A}\end{array}$ & $\begin{array}{l}\mathrm{T} \\
\mathrm{T}\end{array}$ & $\begin{array}{l}\mathrm{MH} \\
\mathrm{MH}\end{array}$ & $\begin{array}{l}\text { A } \\
\text { A }\end{array}$ \\
\hline $\begin{array}{l}\text { Malphigiaceae } \\
\text { Stigmaphyllon bonariense (Hook. \& Arn.) C. E. Anderson }\end{array}$ & IS-LB & E & $\mathrm{T}$ & BH & A \\
\hline $\begin{array}{l}\text { Melastomaceae } \\
\text { Tibouchina nitida (Graham) Cogn. }\end{array}$ & IS-LB & H-AR & $\mathrm{T}$ & $\mathrm{MH}$ & $\mathrm{E}$ \\
\hline $\begin{array}{l}\text { Moraceae } \\
\text { Dichondra sericea Sw. } \\
\text { Morus alba L. }\end{array}$ & $\begin{array}{l}\text { IS-LB } \\
\text { IS-LB }\end{array}$ & $\begin{array}{c}\mathrm{H} \\
\mathrm{AR}\end{array}$ & $\begin{array}{l}\mathrm{T} \\
\mathrm{T}\end{array}$ & $\begin{array}{l}\text { CR } \\
\text { B }\end{array}$ & $\begin{array}{c}\text { A } \\
\text { I }\end{array}$ \\
\hline $\begin{array}{l}\text { Myrtaceae } \\
\text { Eucalyptus globulus Labill. }\end{array}$ & IS-HT & AR & $\mathrm{T}$ & B & I \\
\hline
\end{tabular}


Tabla 2 (cont.)

\begin{tabular}{l}
\hline Taxones \\
\hline Oleaceae \\
Fraxinus pennsylvanica Marshall \\
Ligustrum lucidum W. T. Aiton \\
L. sinense Lour.
\end{tabular}

\section{Onagraceae}

Ludwigia bonariensis (Micheli) H. Hara

L. elegans (Cambess.) H. Hara

\section{Papaveraceae}

Fumaria capreolata L.

\section{Passifloraceae}

Passiflora coerulea L.

\section{Plantaginaceae}

Plantago australis Lam.

P. major L.

P. tomentosa Lam.

\section{Polygonaceae}

Polygonum acuminatum Kunt.

P. punctatum Elliot

\section{Ranunculaceae}

Clematis montevidensis Spreng. var. montevidensis

Ranunculus muricatus $\mathrm{L}$.

R. apiifolium Pers.

\section{Rosaceae}

Rubus ulmifolius Schott

\section{Rubiaceae}

Cephalantus glabratus (Spreng.) K. Schum.

Psychotria carthagenensis Jacq.

\section{Salicaceae}

Populus alba L.

Salix humboldtiana Willd.

\section{Sapindaceae}

Sapium haematospermum Müll. Arg.

\section{Simaroubaceae}

Ailanthus altisima (Mill.) Swingle

\section{Scrofulariaceae}

Verbascum virgatum Stoke

\section{Solanaceae}

Cestrum corymbosum Schltdl.

Solanum glaucophyllum Desf.

S. pseudocapsicum L

S. platense Dieckman
Humedal Hábito Hábitat Fitocenosis Origen

(1)

(2)

(3)

(4)

(5)

$\begin{array}{lllcc}\text { IS-LB } & \text { AR } & \text { T } & \text { B } & \text { I } \\ \text { IS-LB } & \text { AR } & \text { T } & \text { B-BH } & \text { I } \\ \text { IS-LB } & \text { AR } & \text { T } & \text { B-BH } & \text { I } \\ & & & & \\ \text { IS-LB } & \text { A-SA } & \text { T } & \text { CR } & \text { A } \\ \text { IS-LB } & \text { T-SA } & \text { T } & \text { CR } & \text { A }\end{array}$

$\begin{array}{lllll}\text { IS-LB } & \mathrm{H} & \mathrm{T} & \mathrm{MH} & \mathrm{A}\end{array}$

IS-LB E $\quad$ T $\quad$ PM-BH A

IS-LB H $\quad$ T $\quad$ MH $\quad$ A

$\begin{array}{lllll}\text { IS-LB } & \mathrm{H} & \mathrm{T} & \mathrm{MH} & \mathrm{I}\end{array}$

$\begin{array}{lllll}\text { IS-LB } & \mathrm{H} & \mathrm{T} & \mathrm{MH} & \mathrm{E}\end{array}$

$\begin{array}{lllll}\text { IS-LB } & \mathrm{H} & \mathrm{P} & \mathrm{MH} & \mathrm{A}\end{array}$

$\begin{array}{lllll}\text { IS-LB } & \mathrm{H} & \mathrm{P} & \mathrm{MH} & \mathrm{A}\end{array}$

$\begin{array}{lllll}\text { IS-LB } & \text { E } & \text { T } & \text { BH } & \text { A } \\ \text { IS-LB } & \text { H } & \text { T } & \text { MH } & \text { A } \\ \text { IS-LB } & \text { H } & \text { T } & \text { MH } & \text { A }\end{array}$

$\begin{array}{lllll}\text { LB } & \mathrm{H} & \mathrm{T} & \mathrm{BH} & \mathrm{N}\end{array}$

IS-LB A $\quad$ T $\quad$ BH $\quad$ A

$\begin{array}{lllll}\text { IS-LB } & \mathrm{A} & \mathrm{T} & \mathrm{BH} & \mathrm{A}\end{array}$

IS-LB-HT AR T $\quad$ B $\quad$ I

IS-LB-HT AR $\quad$ T $\quad$ BH $\quad$ A

IS-LB AR $\quad$ T $\quad$ BH $\quad$ A

IS-LB-HT AR T $\quad$ B $\quad$ N

$\begin{array}{lllll}\text { IS-LB } & \mathrm{H} & \mathrm{T} & \text { PM } & \mathrm{N}\end{array}$

$\begin{array}{ccccc}\text { IS } & \text { SA } & \text { T } & \text { MH } & \text { N } \\ \text { IS-LB } & \text { SA } & \text { T-P } & \text { MH } & \text { A } \\ \text { IS-LB } & \text { SA } & \text { T } & \text { MH } & \text { A } \\ \text { IS-LB } & \text { SA } & \text { T } & \text { MH } & \text { A }\end{array}$


Tabla 2 (cont.)

\begin{tabular}{lccccc}
\hline Taxones & $\begin{array}{c}\text { Humedal } \\
(\mathbf{1})\end{array}$ & $\begin{array}{c}\text { Hábito } \\
(\mathbf{2})\end{array}$ & $\begin{array}{c}\text { Hábitat } \\
\mathbf{( 3 )}\end{array}$ & $\begin{array}{c}\text { Fitocenosis } \\
(\mathbf{4})\end{array}$ & $\begin{array}{c}\text { Origen } \\
\mathbf{( 5 )}\end{array}$ \\
\hline $\begin{array}{l}\text { Verbenaceae } \\
\text { Verbena intermedia Gill et Hook }\end{array}$ & IS-HT & H & T & B & $\mathrm{N}$
\end{tabular}

\section{Monocotiledóneas}

\section{Alismataceae}

Echinodorus grandiflorus (Cham. \& Schltdl.) Micheli Sagittaria sagittifolia L.

\begin{tabular}{|c|c|c|c|c|}
\hline IS-LB & $\mathrm{H}$ & $P$ & CR-PM & A \\
\hline IS-LB & $\mathrm{H}$ & P-T & CR & A \\
\hline IS-LB-HT & $\mathrm{H}$ & $\mathrm{T}$ & CR & A \\
\hline IS & $\mathrm{H}$ & $\mathrm{T}$ & MH & A \\
\hline LB & $\mathrm{H}$ & $\mathrm{T}$ & CR & A \\
\hline IS-LB & $\mathrm{H}$ & $\mathrm{T}$ & $\mathrm{BH}$ & $\mathrm{N}$ \\
\hline HT & $\mathrm{H}$ & $\mathrm{AF}$ & --- & A \\
\hline IS-LB & EP & $\mathrm{T}$ & B-BH & A \\
\hline IS-LB & $\mathrm{H}$ & $\mathrm{T}$ & $\mathrm{BH}$ & A \\
\hline IS-LB & $\mathrm{H}$ & $\mathrm{T}$ & BH & A \\
\hline IS & $\mathrm{H}$ & $\mathrm{T}$ & $\mathrm{BH}$ & A \\
\hline IS-LB & $\mathrm{H}$ & $\mathrm{T}$ & $\mathrm{MH}$ & E \\
\hline IS-LB & $\mathrm{H}$ & $\mathrm{T}$ & $\mathrm{MH}$ & A \\
\hline IS-LB-HT & $\mathrm{H}$ & $\mathrm{T}$ & $\mathrm{MH}$ & A \\
\hline LB & $\mathrm{H}$ & $\mathrm{T}$ & MH & A \\
\hline LB & $\mathrm{H}$ & $P$ & $\mathrm{MH}$ & A \\
\hline IS & $\mathrm{H}$ & $\mathrm{T}$ & $\mathrm{MH}$ & A \\
\hline IS & $\mathrm{H}$ & $\mathrm{T}$ & PM & A \\
\hline IS-LB-HT & $\mathrm{H}$ & $\mathrm{T}$ & $\mathrm{MH}$ & $\mathrm{N}$ \\
\hline IS & $\mathrm{H}$ & $\mathrm{T}$ & CR & A \\
\hline IS-LB & $\mathrm{H}$ & $\mathrm{T}$ & PM & I \\
\hline IS-LB & $\mathrm{H}$ & $\mathrm{T}$ & PM & A \\
\hline IS-LB & $\mathrm{H}$ & $\mathrm{P}$ & PM & A \\
\hline IS-LB & $\mathrm{H}$ & $\mathrm{T}$ & PM & A \\
\hline IS-LB & $\mathrm{H}$ & $\mathrm{T}$ & CR & $\mathrm{N}$ \\
\hline IS-LB & $\mathrm{H}$ & $\mathrm{P}$ & PM & I \\
\hline IS & $\mathrm{H}$ & $\mathrm{T}$ & CR & E \\
\hline IS-LB & $\mathrm{H}$ & $\mathrm{T}$ & CR & A \\
\hline
\end{tabular}

\section{Amaryllidaceae}

Habranthus gracilifolius Herb.

H. jasmesonii (Baker) Ravenna

Zephyranthes candida (Lind.) Herb.

\section{Araceae}

Lemna gibba $\mathrm{L}$.

Philodendron tweedianum Schott

\section{Bromeliaceae}

Tillandsia aeranthos (Loisel.) L. B. Sm.

\section{Commelinaceae}

Commelina erecta L.

Tradescantia fluminensis Vell.

Tripogandra diuretica (Mart.) Handlos.

\section{Cannaceae}
Canna ascendens Ciciarelli
C. coccinea Miller
C. indica L.
C. glauca L.
C. $x$ generalis Bayley
C. variegatifolia Ciciarelli

\section{Cyperaceae}

Carex bonariensis Desf. ex Poir

Cyperus prolixus Kunth

Heleocharis montana (Kunth) Roem. \& Schult.

Schoenoplectus californicus (C. A. Mey.) Steud.

S. californicus subsp. tatora (Kunth) T. Koyama

Scirpus giganteus Kunth

\section{.}


Tabla 2 (cont.)

\begin{tabular}{|c|c|c|c|c|c|}
\hline Taxones & $\begin{array}{l}\text { Humedal } \\
\text { (1) }\end{array}$ & $\begin{array}{l}\text { Hábito } \\
\text { (2) }\end{array}$ & $\begin{array}{l}\text { Hábitat } \\
\text { (3) }\end{array}$ & $\begin{array}{l}\text { Fitocenosis } \\
\text { (4) }\end{array}$ & $\begin{array}{c}\text { Origen } \\
(5)\end{array}$ \\
\hline $\begin{array}{l}\text { Juncaceae } \\
\quad \text { Juncus pallescens Lam. }\end{array}$ & IS-LB & $\mathrm{H}$ & $\mathrm{T}$ & CR & A \\
\hline $\begin{array}{l}\text { Liliaceae } \\
\quad \text { Nothoscordum gracile (Aiton) Stearn }\end{array}$ & IS-LB & $\mathrm{H}$ & $\mathrm{T}$ & PM & A \\
\hline $\begin{array}{l}\text { Limnocharitaceae } \\
\text { Hydrocleys nymphoides (Willd.) Buchenau }\end{array}$ & HT & $\mathrm{H}$ & A & 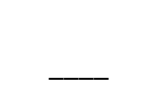 & A \\
\hline $\begin{array}{l}\text { Marantaceae } \\
\text { Thalia geniculata } \mathrm{L} .\end{array}$ & HT & $\mathrm{H}$ & $\mathrm{P}$ & PM & A \\
\hline $\begin{array}{l}\text { Pontederiaceae } \\
\text { Eichornia azurea (Sw.) Kunth } \\
\text { E. crassipes (Mart.) Solms } \\
\text { Pontederia cordata var. lancifolia (Muhl. ex Ell.) Torr. } \\
\text { P. lanceolata Nutt. }\end{array}$ & $\begin{array}{l}\text { IS-LB- HT } \\
\text { IS-LB- HT } \\
\text { IS-LB } \\
\text { IS-LB }\end{array}$ & $\begin{array}{l}\mathrm{H} \\
\mathrm{H} \\
\mathrm{H} \\
\mathrm{H}\end{array}$ & $\begin{array}{c}\mathrm{AF} \\
\mathrm{AF} \\
\mathrm{A} \\
\mathrm{A}\end{array}$ & $\begin{array}{l}\text { CR } \\
\text { CR } \\
\text { CR } \\
\text { CR }\end{array}$ & $\begin{array}{l}\mathrm{A} \\
\mathrm{A} \\
\mathrm{A} \\
\mathrm{A}\end{array}$ \\
\hline $\begin{array}{l}\text { Smilacaceae } \\
\quad \text { Smilax campestris Griseb. }\end{array}$ & IS-LB & E & $\mathrm{T}$ & PM & A \\
\hline $\begin{array}{l}\text { Typhaceae } \\
\text { Thypha latifolia L. }\end{array}$ & IS-LB & $\mathrm{H}$ & $\mathrm{P}$ & AA & A \\
\hline $\begin{array}{l}\text { Zingiberaceae } \\
\text { Hedychium coronarium Konig } \\
\text { H. gardnerianum Sheppard ex Ker Gawl. }\end{array}$ & $\begin{array}{l}\text { IS-LB } \\
\text { IS-LB }\end{array}$ & $\begin{array}{l}\mathrm{H} \\
\mathrm{H}\end{array}$ & $\begin{array}{l}\mathrm{T} \\
\mathrm{T}\end{array}$ & $\begin{array}{l}\mathrm{MH} \\
\mathrm{MH}\end{array}$ & $\begin{array}{l}\mathrm{I} \\
\mathrm{I}\end{array}$ \\
\hline Pteridófitos & & & & & \\
\hline $\begin{array}{l}\text { Adiantaceae } \\
\quad \text { Adiantum raddianum C. Presl }\end{array}$ & LB & $\mathrm{H}$ & $\mathrm{T}$ & $\mathrm{BH}$ & A \\
\hline $\begin{array}{l}\text { Aspleniaceae } \\
\text { Asplenium sellowianum (Hieron.) C. Presl ex Hieron }\end{array}$ & IS-LB & $\mathrm{H}$ & $\mathrm{T}$ & $\mathrm{BH}$ & A \\
\hline $\begin{array}{l}\text { Azollaceae } \\
\quad \text { Azolla filiculoides Lam. }\end{array}$ & IS-HT & $\mathrm{H}$ & A & $\mathrm{AF}$ & A \\
\hline $\begin{array}{l}\text { Equisetaceae } \\
\text { Equisetum giganteum Michx. ex DC. }\end{array}$ & LB & $\mathrm{H}$ & $\mathrm{P}$ & HT & A \\
\hline $\begin{array}{l}\text { Blechnaceae } \\
\text { Blechnum australe L. subsp. australe } \\
\text { B. levigatum Cav. } \\
\text { B. occidentale L. }\end{array}$ & $\begin{array}{l}\text { IS-LB } \\
\text { IS-LB } \\
\text { IS-LB }\end{array}$ & $\begin{array}{l}\mathrm{H} \\
\mathrm{H} \\
\mathrm{H}\end{array}$ & $\begin{array}{l}\mathrm{T} \\
\mathrm{T} \\
\mathrm{T}\end{array}$ & $\begin{array}{l}\mathrm{MH} \\
\mathrm{MH} \\
\mathrm{MH}\end{array}$ & $\begin{array}{l}\mathrm{A} \\
\mathrm{A} \\
\mathrm{A}\end{array}$ \\
\hline $\begin{array}{l}\text { Pteridaceae } \\
\quad \text { Pteris vittata L. }\end{array}$ & IS-LB & $\mathrm{H}$ & $\mathrm{T}$ & $\mathrm{MH}$ & I \\
\hline $\begin{array}{l}\text { Polypodiaceae } \\
\text { Microgramma vaccinifolia (Langsd. \& Fisch) Copel } \\
\text { Pleopeltis macrocarpa (Bory ex Willd.) Kaulf. }\end{array}$ & $\begin{array}{l}\text { IS } \\
\text { IS }\end{array}$ & $\begin{array}{l}\mathrm{H} \\
\mathrm{H}\end{array}$ & $\begin{array}{l}\text { EP } \\
\text { EP }\end{array}$ & $\begin{array}{l}\mathrm{BH} \\
\mathrm{BH}\end{array}$ & $\begin{array}{l}\mathrm{A} \\
\mathrm{A}\end{array}$ \\
\hline $\begin{array}{l}\text { Thelypteridaceae } \\
\text { Thelypteris riograndensis (Lindm.) C. F. Reed }\end{array}$ & IS & $\mathrm{H}$ & $\mathrm{T}$ & MH & A \\
\hline
\end{tabular}


constantes inundaciones. El suelo es arenoso, blando y se fija por la presencia de un juncal costero, sometido a constantes crecidas que se prolonga a lo largo de la margen del río, está integrado por especies de Scirpus, Schoenoplectus y Eleocharis, por sectores asociado con gramíneas, como Paspalum vaginatum Sw. y Panicum decipiens Nees (Fig. 2A). Lo sucede un césped ribereño muy bajo y extenso, que ocupa el área de constantes inundaciones formado principalmente por Gomphrena elegans, Hydrocotyle ranunculoides, Cardamine bonariensis y Cardamine hirsuta. Continúan el verdolagal, una comunidad de poca diversidad aunque de gran extensión, en el que las plantas jóvenes crecen sobre un estrato denso de follaje de plantas secas que dan resistencia al suelo anegadizo e inundable, pero más firme que en el juncal dominado por Ludwigia elegans, Hydrocotyle leucocephala, Lilaeopsis brasiliensis, Cuphea fructicosa y Eryngium pandanifolium (Fig. 2A); el pajonal mixto, integrado por elementos palustres herbáceos, arbustivos, volubles y lianas, donde se encuentran representantes de los géneros Canna, Cuphea, Eryngium, Hydrocotyle, Ipomoea, Iris, Lonicera, Ludwigia, Passiflora, Pavonia, Polygonum, Pontederia, Sagittaria, Schoenoplectus, Tradescantia, Trifurcia y Tripogandra. En esta asociación aparecen equisetáceas como Equisetum giganteum $\mathrm{y}$ helechos leptosporangiados, como Blechnum australe subsp. australe, B. levigatum, B. occidentale y Thelypteris riograndensis, en el lecho de los canales cercanos inundables se observan Miriophyllum y Enydra mientras que en sus márgenes crecen Thalia geniculata y Typha. (Fig. 2C); el estrato arbóreo está formado por un bosque hidrófilo (Fig. 2A-B) con especies de los géneros Erihtrina, Salix, Tessaria, Phyllantus, Sesbania y Sapium forman extensas comunidades arbóreas asociadas con los elementos palustres mencionados. El estrato más bajo (3-15 m) presenta Cephalanthus glabratus, Erythryna crista-galli y Tessaria integrifolia y en el estrato más alto (10-20 m) abundan Sapium haematospermum y Salix humboldtiana. Además, en el bosque hidrófilo coexisten taxones introducidos, arbustivos o arbóreos, como Acer negundo, Populus alba, dos especies de Ligustrum y Fraxinus pennsylvanica. Entre las enredaderas Rubus ulmifolius se encuentra en franca expansión y compite con las especies autóctonas.

Para este humedal se registraron 33 familias, 56 géneros y 65 especies de dicotiledóneas; 16 familias, 22 géneros y 36 especies de monocotiledóneas y 5 familias, 5 géneros y 7 especies de pteridófitos (Tabla 2).

Humedal de Isla Santiago (Fig. 3). Se encuentra en el Partido de Ensenada (34 $51^{\prime} 25^{\prime \prime}$ S 57 54'27"O, Fig. 1B). La isla natural preexistente se dividió en dos por la construcción del Puerto de La Plata en el año 1883 y quedaron delimitadas artificialmente, la Isla Paulino y la Isla Santiago. La Isla Santiago es una bahía costera, protegida por un pequeño muelle, en donde las aguas tienen escasa corriente y por eso constituye la zona menos expuesta del río, con ambiente léntico (Fig. 3A, B). El terreno es bajo y la altura máxima sobre el nivel del mar es de $4 \mathrm{~m}$; tiene una extensión de 4,22 km de longitud y una anchura de $2,36 \mathrm{~km}$. La vegetación de la bahía, comprende plantas acuáticas sumergidas, flotantes y arraigadas que forman comunidades densas (Fig. 3A, B, C) de elementos arraigados como Pontederia cordata, P. rotundifolia, Echinodorus grandiflorus y Sagittaria montevidensis. Además, se observan grandes extensiones de Panicum elephantipes Nees ex Trin, y Myriophyllum aquaticum (Fig. 3B). Abundan los camalotales cuya extensión fluctúa en relación directa con los períodos de lluvia e inundaciones y también con los aportes de los ríos Paraná y Uruguay, cuyas aguas incrementan el caudal de esta zona constituidos por especies flotantes como Eichornia crassipes y E. azurea. Estas poblaciones han sido particularmente abundantes entre 2005 y 2008 para disminuir y hasta desaparecer de la zona de la bahía entre 2009 y 2011 (Tabla 1). La vegetación terrestre incluye césped ribereño, un estrato herbáceo y muscinal, con hierbas de escasa altura como Juncus pallescens y Heleocharis montana, además de especies palustres de mayor porte como Sagittaria montevidensis y Pontederia cordata, habituales en momentos de inundación y aloja especies palustres de mayor porte; seguido del pajonal, integrado por hierbas, enredaderas y también plantas más altas que crecen en la orilla pero son raras 0 ausentes en la zona del suelo no inundable, como especies de Commelina, Tradescantia, Zizaniopsis, Cuphea, Cyperus, Hydrocotyle, Ipomoea y otras plantas que alcanzan mayor desarrollo, como especies de Ludwigia, Schoenoplectus, Scirpus, Senecio y Solanum que crecen en la orilla, siempre en la zona inundable (Fig. 3B-C). Luego del pajonal continúa un matorral herbáceo que se asocia con arbustos de desarrollo variable pertenecientes a Canna, Eryngium, Gomphrena, Hedychium, Sesbania, Tradescantia y enredaderas de los géneros Ipomoea, Lonicera, Passiflora y Stigmatophyllum. En este matorral son comunes los helechos, como Blechnum australe subsp. australe, $B$. levigatum, B. occidentale y Thelypteris riograndensis, asociados con hierbas y enredaderas; el bosque hidrófilo (Fig. 3A) se encuentra representado por especies arbóreas autóctonas, con escasa diversidad de epífitos, de los géneros Salix, Tessaria, Phyllantus, Sesbania y Sapium; Eryhthrina crista-galli y Salix humboldtiana. Los epífitos son escasos en diversidad pero las especies de Microgramma y Rhipsalis son localmente abundantes. También 

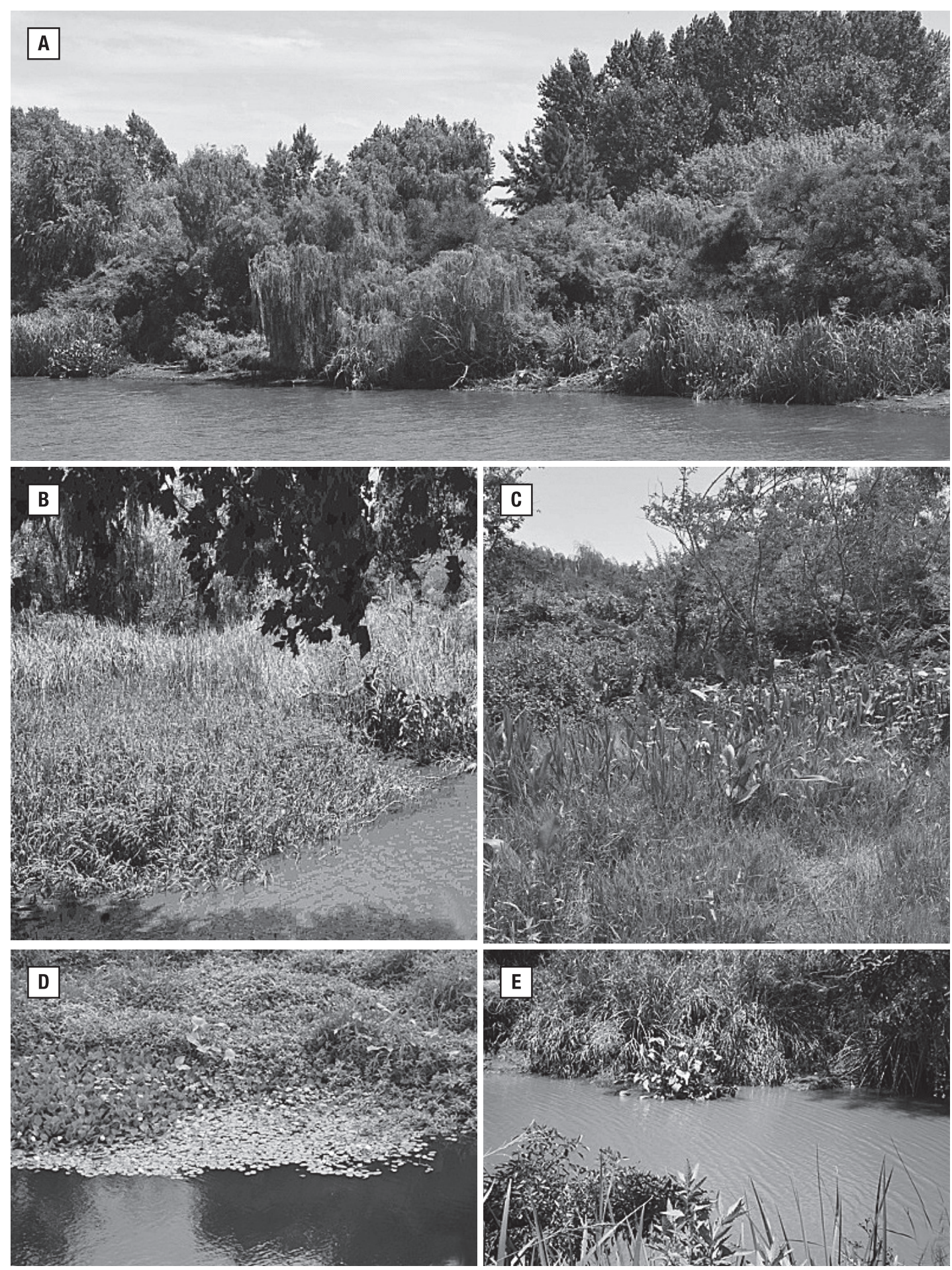

Fig. 3- Humedal permanente de Isla Santiago y humedales transitorios. A: sucesión de césped ribereño, matorral herbáceo y bosque hidrófilo; B: Panicum elephantipes, en comunidad densa, encharcada, en la orilla misma y en el lecho barroso; C: Sagittaria sagittifolia, en comunidad densa junto al bosque hidrófilo; D: arroyo Rodríguez, con comunidad de plantas acuáticas flotantes; E: canal cercano al acceso a la playa La Balandra. 
hay algunos árboles introducidos como Acer negundo, Populus alba var. pyramidalis y Ligustrum lucidum. Los pastizales de las áreas de acceso al humedal están integrados por comunidades densas de Cortaderia selloana (Schult.) Asch. et Graeb, Stipa neesiana Trin. et Rupr., Botriochloa sp. y Salix humbodltiana, también abundante en esta zona. En zonas abiertas, entre el matorral y el bosque hidrófilo, aparece Iris pseudacorus, una especie invasora que se extiende formando extensas poblaciones asociada a ejemplares más o menos aislados de Eryhthrina cristagalli y Acer negundo (Fig. 3).

Para este humedal se registraron 36 familias, 64 géneros y 74 especies de dicotiledóneas; 16 familias, 25 géneros y 31 especies de monocotiledóneas y 6 familias, 7 géneros y 9 especies de pteridófitos (Tabla 2).

Humedales transitorios (Fig. 3 D-E). Los humedales transitorios estudiados se extienden a lo largo de arroyos y pequeños canales de terrenos bajos que atraviesan sitios urbanizados y circulan en una amplia zona de producción hortícola de La Plata y las localidades de City Bell, Gonnet y Ringuelet (Fig. 1A). En estos sitios la flora y fauna natural se ven afectadas por la creciente urbanización, el avance de la flora naturalizada 0 cultivada y en algunos sitios, por la descarga de desechos cloacales y el saneamiento frecuente para enfrentarla. El curso de los arroyos se acelera con las lluvias frecuentes pero la falta de lluvias aumenta la densidad por la carga alóctona artificial. En los años finales de este estudio fueron crecientes los asentamientos humanos provisorios en las márgenes de los canales y arroyos. Los sitios analizados se eligieron por su aislamiento y se encuentran a lo largo del arroyo Rodríguez y arroyo El Gato, destacados porque presentan una flora particular, integrada por una interesante asociación de flora prístina y vegetación cultivada (Fig. 1A). Se incluye aquí la flora del canal de la calle 66 que comunica a la ciudad de La Plata con la ciudad de Berisso, ubicado a sólo $7 \mathrm{~km}$ del camino de acceso a La Balandra, que presenta variaciones en el flujo de agua de acuerdo con los cambios estacionales del río.

Arroyo Rodríguez. Este arroyo tiene un recorrido de $20 \mathrm{~km}$ y un ancho de 3-6 m; con un cauce fluctuante a 10 largo de su extensión. Se seleccionaron dos zonas representativas:

1. En la localidad de City Bell, en la zona en que el arroyo cruza el camino Parque Centenario, el cauce es ancho y hay comunidades flotantes de Azolla filiculoides, Hydrocleys nymphoides, Lemna gibba y palustres, de Alternanthera phylloxeroides, Eichornia azurea, Echinocloa polystachya (Humb. \& Bonpl. ex Kunth) Hitchc., Hydrocotyle bonarienseis y Sagittaria montevidensis, con un abundante césped ribereño integrado por Acmella decumbens, Canna coccinea, Canna indica y gramíneas de los géneros Stipa y Paspalum. (Fig. 3 D).

2. En la zona en que el arroyo cruza el camino General Belgrano los márgenes difieren en el tipo de vegetación: en tanto el margen noroeste presenta árboles cultivados muy desarrollados, como Acer negundo, Eucalyptus globulus, Fraxinus americana, Robinia pseudo acacia y Salix humboldtiana, el margen opuesto carece de vegetación arbórea y en el cesped ribereño crecen plantas herbáceas silvestres como Arundo donax, Canna indica, C. variegatifolia, Cyclanthera aff. pedata, Cyperus prolixus, Ipomoea purpurea y Paspalum quadrifarium Lam. El curso de agua no presenta vegetación flotante. En dirección E, sobre el mismo margen, se presentan extensas poblaciones de Canna indica, con plantas que alcanzan gran altura y que ocupan un área aproximada de $900 \mathrm{~m}^{2}$. También crecen hierbas, como Aspilia silphioides y Conium maculatum. Hay un estrato arbustivo con Manihot flabellifolia y grandes Eucalyptus globulus (Fig. 3E) pero la flora se ve reducida por los frecuentes saneamientos.

Arroyo El Gato. En la localidad de Ringuelet, en la zona en que el arroyo El Gato cruza el camino Parque Centenario se presentan asociaciones de plantas silvestres en terrenos bajos inundables: Canna ascendens, C. coccinea, Ipomoea purpurea, Manihot flavellifolia, y a lo largo de ese camino, en dirección a City Bell, hay asociaciones de Typha latyfolia, Salix humboldtiana, y una zona de pastizal con abundante Arundo donax y Stipa sp.

Canal natural entre Gonnet-City Bell. Siguiendo el trazado de las vías férreas y a pocos metros al este del Camino Centenario cursa un ancho zanjón que alberga comunidades silvestres: Acmella decumbens, Amaranthus quitensis, Arundo donax, Erithryna crista-galli, Paspalum quadrifarium, Manihot flabellifolia, Sagittaria montevidensis, Senecio bonariensis, Solidago chilensis, Typha latifolia, juntamente con árboles cultivados como Ailanthus altissima y Populus alba. En el lado oeste del mismo camino, los zanjones presentan asociaciones de Erytryna crista-galli, Sagittaria montevidensis y Typha latifolia. En la parte más alta de los zanjones crecen Canna ascendens y $C$. indica.

Humedales suburbanos de City Bell. En pequeños humedales relictuales Canna indica vive en asociación con Acmella decumbens, Iris pseudacorus, Typha latifolia, Verbena intermedia y Sagittaria montevidensis.

Canal Calle 66. En la zona de este canal se presentan comunidades acuáticas densas que están en marcado retroceso desde 2006 por repetido saneamiento y dragado. 
Persisten especies autóctonas, como Thalia geniculata, que crece asociada a Eichornia crassipes (Fig. 1D).

\section{DISCUSIÓN Y CONCLUSIONES}

En los humedales permanentes, pese a su cercanía con áreas habitadas, se presentan sitios con abundante vegetación autóctona. Las fitocenosis halladas corresponden a comunidades de plantas acuáticas flotantes (camalotales), acuáticas arraigadas (juncales), césped ribereño, pajonal mixto, matorral herbáceo y bosque hidrófilo (Cabrera et al. 1978), también características de la selva marginal cercana (Punta Lara) y de las selvas del NE del país y del Chaco húmedo.

La dinámica de estas fitocenosis se ve afectada principalmente por las diferencias en las precipitaciones anuales, que fluctúan entre años más y menos lluviosos. En la Isla Santiago las fluctuaciones anuales del nivel del río parecen haber influido en variaciones locales del desarrollo de los camalotales, el césped ribereño y el pajonal. En años con precipitaciones más abundantes (2005, 2006, 2007 y 2009) el desborde del río alteró las comunidades, con mengua o desaparición del camalotal y gran parte de las plantas flotantes quedaron secas sobre la orilla y sobre el césped ribereño, que redujo su extensión por invasión de especies típicas del pajonal, como Scirpus giganteus y Typha latifolia. En los años con menos precipitaciones (2008 y 2011) se observó que el descenso del nivel del río y el aumento de sedimento permitió un mayor desarrollo de los camalotales y del césped ribereño, con el pajonal más alejado de la orilla y más cercano al bosque hidrófilo. Estos datos son importantes porque las plantas flotantes han sido consideradas invasoras y causantes de diversos problemas como la obstrucción de arroyos y canales, y el impedimento del crecimiento y desarrollo de otras especies de plantas y de animales asociados.

Otros factores que han afectado localmente las comunidades estudiadas son la prolongación de temperaturas estivales y el retraso en la aparición de las primeras heladas desde el mes de mayo hasta junio o julio, algo que ha ocurrido en el lapso del estudio y parece haber prolongado el ciclo de vida de muchas plantas herbáceas como Canna indica (Ciciarelli 2012), Iris pseudacorus, Sagittaria montevidensis y Scirpus giganteus que florecen hasta el mes de junio, mientras que otras, como Arundo donax, Cortaderia selloana y Typha latifolia, más resistentes a las heladas, persisten en invierno y continúan liberando semillas en esa estación.

Las comunidades estudiadas son las de mayor diver- sidad de la Provincia. Sin embargo se trata de comunidades empobrecidas respecto de las zonas de selva en galerías ubicadas en el noreste del país.

Al comparar los datos obtenidos en los ambientes permanentes, lénticos y lóticos, se puede observar que, si bien muchos taxones aparecen en ambos, la distribución $\mathrm{y}$ asociaciones difieren. La Balandra tiene una playa amplia que bordea el río, una condición que permite un mayor desarrollo de los juncales, comunidades que son poco extensas en Isla Santiago. En general, el humedal de La Balandra presenta una menor diversidad que el de la Isla Santiago; sin embargo la flora está mejor conservada y esto podría deberse a distintos factores favorables como la mayor extensión de costa y la consecuente fijación más efectiva del suelo inundable, la ausencia de población estable en la zona del humedal, que permite la conservación de vegetación original en una sucesión no interrumpida de comunidades acuáticas y palustres que se encuentran en un estado de conservación bueno, con un grado de intervención relativamente baja. Es frecuente hallar aquí extensas áreas de pajonales y de bosque hidrófilo de difícil acceso.

Los bosques hidrófilos están presentes en los dos humedales permanentes, especialmente con elementos muy típicos: sauces autóctonos que se asocian con ceibales (Erythryna crista-galli) para formar extensas comunidades en zonas inundables. También Eleocharis aparece en zonas de crecida 0 en asociación con gramíneas como Paspalum vaginatum y Panicum decipiens. Los pajonales de cortadera (Scirpus giganteus) ocupan áreas de menor inundación, al borde del río, en las zonas de acceso a ambos humedales.

Los camalotales se expanden rápidamente en las zonas con ambiente léntico, en las que es posible encontrar todas las especies (Eichornia crassipes, E. azurea, Pontederia cordata y $P$. rotundifolia). Las comunidades de matorral herbáceo se ven afectadas por las crecidas en la Isla Santiago, porque en este humedal se localizan a pocos metros del río, en tanto que en La Balandra se encuentran más distantes del cauce más profundo. Las plantas acuáticas, flotantes 0 arraigadas, son más frecuentes en los canales que vierten sus aguas en el Río de La Plata, que son angostos y de poca corriente, por lo que se asemejan localmente a los humedales transitorios estudiados.

Respecto a los humedales transitorios, Sagittaria montevidensis y Typha latifolia forman asociaciones muy abundantes, están presentes en las orillas de los arroyos y en zanjones y terrenos inundables de escasa extensión, zonas aledañas a caminos y calles cercanas a esos cuerpos de agua. En menor proporción crecen especies de Cype- 
rus y Canna, aunque varias especies de este género crecen encharcadas en los pajonales de todos los humedales, permanentes o transitorios, a veces formando asociaciones con Iris pseudacorus (sólo en La Balandra). Thalia geniculata, es común en humedales del centro y E del país y llega a la ribera platense, aunque no es abundante en los humedales estudiados y crece encharcada sólo en los canales cercanos a la localidad de Berisso. En áreas más secas, aledañas a los humedales, las asociaciones son las típicas del pastizal (gramíneas de los géneros Cortaderia, Stipa, Botriochloa, Paspalum, Poa y Zizaniposis). La flora del Arroyo Rodríguez se reduce anualmente por dragado y limpieza de sus orillas, particularmente desde 2008; por otra parte, el avance de especies cultivadas y la urbanización desordenada constituyen factores que atentan contra la flora y fauna silvestre del arroyo.

El avance de la urbanización en zonas ribereñas, principalmente en la Isla Santiago, ocasiona erosión, empobrecimiento del suelo y cambios en el balance hídrico por efecto de rellenos, canalizaciones y riego. La cercanía de industrias y sus efluentes contaminan las aguas de arroyos y canales deteriorando aún más el ambiente.

Si bien en la vegetación de estos sitios existen elementos biorremediadores como especies de Cyperus, Eichornia, Hydrocotile, Ipomoea, Lemna, Pistia y Typha, que metabolizan los productos tóxicos presentes en el agua y los transforman en componentes inocuos o los almacenan en sus tejidos, constituyen a la vez un riesgo para la fauna herbívora que consume a estas plantas con una mayor concentración de contaminantes y los reintroduce a la red trófica.

Otro factor negativo, importante en ambos sitios de humedal permanente, es el creciente avance de especies introducidas que son una amenaza para las especies nati- vas. Una muy abundante es Ligustrum lucidum cuyo predominio sobre la flora nativa se atribuye a la efectividad de sus recursos reproductivos (Montaldo 1993). De acuerdo a lo observado aquí, Ligustrum sinensis es invasora en los matorrales herbáceos y otras especies, incluso nativas, como Arundo donax, Canna indica, Sagittaria montevidensis, Ipomoea purpurea e I. indica, endémicas como Scirpus giganteus, cosmopolitas como Typha latifolia 0 alóctonas, como Iris pseudoachorus generan comunidades crecientemente abundantes que invaden áreas de La Balandra, Isla Santiago y selvas marginales cercanas como la de Quilmes y Ribera Norte.

Las acciones para mantener las zonas prístinas e impedir el deterioro creciente de la vegetación original de las mismas debería incluir una acción conjunta de los municipios, con el fin de mantener el estado actual del ecosistema y tratar de revertir los daños observados, así como educar a la población para alentar el uso de especies silvestres y no introducidas, cuidar el saneamiento de los canales respetando las especies que allí habitan y restringir las construcciones recreativas en zonas como La Balandra y playas de la ribera.

\section{AGRADECIMIENTOS}

Este estudio fue realizado en el Laboratorio de Estudios de Anatomía Vegetal Evolutiva y Sistemática (LEAVES) de la Universidad Nacional de La Plata,con aportes del Programa de Incentivos para Docentes Investigadores de la Universidad Nacional de La Plata, Proyecto $\mathrm{N}^{\circ} 697$; y del Consejo Nacional de Investigaciones Científicas y Técnicas (CONICET) al que pertenecen Graciela González y Cristina Rolleri. Las autoras agradecen a Arturo Wulff y revisores anónimos por sus valiosas críticas, y a Marcos G. Moreno por la diagramación y la edición digital de las imágenes.

Arbo, M. M. \& Tressens, S. G. (Eds.) 2002. Flora del Iberá.

\section{BIBLIOGRAFÍA}

Eudene. Editorial Universitaria Universidad Nacional del Nordeste, Corrientes.

Barbetti, R.; Ronnchetti, A. \& ChéBez, J. C. 1985. Refugio Educativo de la Ribera Norte. Partido de San Isidro, provincia de Buenos Aires. Fundación Vida Silvestre Argentina.

Barbier, E. B.; Acreman, M. C. \& Knowler, D. 1997. Valoración económica de los humedales. Guía para decisiones y planificadores. Oficina de la convención de Ramsar. Gland.

BEERLING, D. J. 1995. General aspects of plant invasions: an overview. En: P. Pysek et al. (Eds.), Plant invasions: general aspects and special problems. SPB, Amsterdam.

Bertolini, P. \& Deginani, N. 1994. Relevamiento de especies del Refugio Educativo de la Ribera Norte. Informe técnico. Municipalidad de San Isidro.

Bridson, D. M. \& Forman, L. L. (Eds.) 1992. The herbarium handbook, ed. 3. Royal Botanic Gardens, Kew.

BURKART, A. E. 1957. Ojeada sinóptica sobre la vegetación del Delta del Río Paraná. Darwiniana 11(3): 475-563.

Burkart, A. E.; Troncoso, N. \& Bacigalupo, N. 1987. Flora de Entre Ríos. Col. Ci. INTA 6(3): 1-763.

Burkart, R.; BÁrbaro, N.; SÁnchez, R. \& Gómez, D. 2000. Eco-regiones de la Argentina. APN-Secretaría de Recursos Naturales y Desarrollo Sustentable de la Nación, Buenos Aires.

BurKart, S.; LeÓN, R. \& Movia, C. 1990. Inventario fitosocio- 
lógico del pastizal de la Depresión del Salado (pcia. de Buenos Aires) en un área representativa de sus principales ambientes. Darwiniana 30(1-4): 27-69.

Cabrera, A. L. 1963-1970. Flora de la Provincia de Buenos Aires, 4. Col. Ci. INTA. Buenos Aires.

Cabrera, A. L. \& Zardini, E. M. 1978. Manual de la flora de los alrededores de Buenos Aires. ACME, Buenos Aires.

Cabrera, A. L. \& Dawson, G. 1944. La selva marginal de Punta Lara. Rev. Mus. La Plata, Secc. Bot. 5: 267-382

Cagnoni, M.; FafFi, A. M. \& Ribichich, A. 1996. La vegetación de la Reserva El Destino (Partido de Magdalena, prov. de Buenos Aires). Parodiana 9(1-2): 25-44.

Canevari, P.; Blanco, P.; Bucher, E.; Castro, G \& Davidson, I. (Eds.) 1998. Los humedales de la Argentina. Clasificación, situación actual, conservación y legislación. Wetlands International Publ. 46, Buenos Aires.

Canevari, P.; Blanco, E. \& Bucher, E. 1999. Los beneficios de los humedales de la Argentina. Amenazas y propuestas de soluciones. Wetlands International Publ., Buenos Aires.

Castellanos, A. \& Pérez Moreau, R. A. 1945. Los tipos de vegetación de la República Argentina. Monografias del Instituto de Estudios Geográficos 4. Universidad Nacional de Tucumán.

CiCiarelli, M. M. 1995. Canna variegatifolia Ciciarelli sp. nov. (Cannaceae-Zingiberales). Rev. Museo La Plata, Bot. 14: 333-341.

Ciciarelli, M.M. 2007. Canna ascendens Ciciarelli (Cannaceae) una nueva especie de la provincia de Buenos Aires y comentarios de otras especies argentinas de este género. Darwiniana 45: 188-200.

CiciarelLI, M. M. 2012. Life cycle in natural populations of Canna indica L. from Argentina. Phenology and Climate Change 6: 101-116.

Ciciarelli, M. M. \& Rolleri, C. H. 2008. Morfología, taxonomía y caracterización de siete especies neotropicales del género Canna (Cannaceae). Bot. Complut. 32: 157-184.

Ciciarelli, M. M., Rolleri, C. H. \& GonzÁlez Duboux, C. 2010. Canna fuchsina (Cannaceae-Zingiberales), una especie nueva para la Argentina y sus relaciones con otras especies silvestres del género y con el grupo C. $x$ generalis. Bot. Complut. 34: 49-55.

Faggi, A. M. \& Cagnoni, M. 1990. Flora del Parque Natural Costanera Sur. Parodiana 6(1): 1-466.

Font Quer, P. 2000. Diccionario de Botánica. Edición Península, Barcelona.

Frusella, S. \& ChÉBez, J. M. 2003. Patrimonio Natural de Argentina. Argentina ambiental 43. www.patrimonionatural.com

Frenguelli, J. 1941. Dicroidium stelznerianum (Geinitz) n. comb. Notas Museo de La Plata 6, Paleontología 33: 393-403.

Goya, G. \& Brown, A. 1992. Distribución y características estructurales de los talares de la Reserva de los Talares de la reserva de la biosfera «Parque Costero del Sur». Revista de la Fac. Agron, La Plata 68: 53-64.

Haynes, R. R. \& Holm Nielsen, L. B. 1994. The Alismataceae. Flora Neotropica, Monog. 64: 1-112.
Judd, W. S.; Campbell, C. S.; Kellog, E. A.; Stevens, P. F. \& Donoghue, M. J. 2002. Plant Systematics. A phylogenetic approach. Sinauer Ass. Inc., Sunderland, Massachusets.

KALESNIK, F. 2001. Relación entre la heterogeneidad ambiental y las comunidades vegetales de los neoecosistemas de albardón de las islas del Bajo Delta del Rio Paraná. Tendencias sobre su composición futura. Tesis doctoral. Fac. CC. Exactas y Naturales, Universidad de Buenos Aires.

Kandus, P. 1997. Análisis de patrones de vegetación a escala regional en el Bajo Delta Bonaerense del Rio Paraná (Argentina). Tesis doctoral. Fac. Cs. Exactas y Naturales. Universidad de Buenos Aires.

Kandus, P.; Kalesnik, F.; Borgo, L. \& Malvárez, A. I. 2000. La Reserva Natural «Isla Botija» en el Delta del Río Paraná: análisis de las comunidades de plantas en el paisaje. $\mathrm{Pa}$ rodiana $12: 3-20$.

Kandus P.; Malvárez, A. I. \& Madanes, A. 2003. Estudio de las comunidades de plantas herbáceas de las islas bonaerenses del Bajo Delta del Río Paraná (Argentina). Darwiniana 41(1-4):1-16.

Lahitte, H. B. \& Hurrell, J. A. 1997. Plantas de la Costa. Las plantas nativas y naturalizadas más comunes de las costas del Delta del Paraná, Isla Martín García y Ribera Platense. Ed. LOLA, Buenos Aires.

MalváREZ, A. I. 1999. Tópicos sobre humedales subtropicales y templados sudamericanos de Sudamérica y el Caribe. Oficina Regional de Ciencia y Técnica de la UNESCO para América Latina y el Caribe.

Menalled, F. \& AdÁMOLI, J. 1995. A quantitative phytogeographic analysis of richness in forest communities of the $\mathrm{Pa}$ raná River Delta, Argentina. Vegetatio 120: 81-90.

Mitsch, W. J. \& Gosselink, J. G. 1993. Wetlands. 2nd Ed. John Wiley \& Sons, New York.

MonTALDO, N. H. 1993. Dispersión por aves y éxito reproductivo de dos especies de Ligustrum (Oleaceae) en un relicto de selva subtropical en la Argentina. Revista Chilena de Historia Natural 66: 75-85.

PARODI, L. 1945. Las regiones fitogeográficas argentinas y sus relaciones con la industria forestal. Plants and plant sciences in Latin America. A new series of Plant Science Books, Edit. Verdoon, Massachussets.

Parodi, L. 1964. Gramineas bonaerenses. 5 ed. Acme Agency, Buenos Aires.

Quintana, R. \& Bó, R. 1998. Actividades humanas y biodiversidad en humedales: el caso del Bajo Delta del Río Paraná. En: J. Morello, O. Solbrig \& S. Matteucci (Eds.), Estilos de desarrollo y conservación de la biodiversidad en América Latina y el Caribe. EUDEBA, Buenos Aires.

Quintana, R; Bó, R. \& KALESNIK, F. 1999. La vegetación y la fauna silvestre de la porción terminal de la cuenca del Plata. Consideraciones biogeográficas y ecológicas. En: J. M. Borthagaray (Ed.), El Río de la Plata como territorio. Fondo Cultura Económica, Buenos Aires.

Rataj, K. 1972. Revision of the genus Sagittaria Part. II. Annot. Zool. Bot. 70: 1-61. 
RogGeri, H. 1995. Tropical freshwater wetlands. A guide to current knowledge and sustainable management. Kluwer Academic Publishers, Dordrecht.

VAlLÉs, L; KALESNiK, F. \& MaLvÁReZ, A. I. 2005. Los parches relictuales de Monte Blanco del área núcleo de la Reserva de Biosfera MAB-UNESCO «Delta del Paraná». En: Manejo y conservación de los humedales del litoral argenti- no. Fundación Proteger, Paraná, Entre Ríos y Wetlands International.

Zuloaga, F.; Morrone, O. \& Belgrano, M. 2008. Catálogo de las plantas vasculares del Cono Sur: Argentina, Sur de Brasil, Chile, Paraguay y Uruguay). Monographs Missouri Botanical Garden, 107. Ed. Missouri Botanical Garden Press, St. Louis. 